\title{
The Influence of SBS, Viatop Premium and FRP on the Improvement of Stone Mastic Asphalt Performance
}

\author{
Sepehr Saedi ${ }^{1, *}$ and Seref Oruc ${ }^{2}$ (1) \\ 1 Departement of Road and Transpotation Civil Engineering, Karadeniz Technical University, \\ Trabzon 61080, Turkey \\ 2 Departement of Civil Engineering, Karadeniz Technical University, Trabzon 61080, Turkey; oruc@ktu.edu.tr \\ * Correspondence: saedi.sepehr@gmail.com; Tel.: +90-5365956864
}

Received: 2 February 2020; Accepted: 19 March 2020; Published: 27 March 2020

\begin{abstract}
The current study investigates the effects of Fiber Reinforce Polymer (FRP) additive on the performance of Stone Mastic Asphalt (SMA) mixtures with SBS and Viatop Premium additives. The asphalt mixture used in the current study included SBS (Styrene-Butadiene-Styrene) additive modified at the rate of $5 \%$ according to the necessary preliminary studies, and some SMA mixture modified by adding FRP (Fiber Reinforced Polymers) additive prepared in dimensions of $5 \mathrm{~cm}$ in different proportions $(0.3 \%, 0.5 \%, 0.7 \%$ and $0.9 \%)$. The mechanical properties of the mixtures were investigated, and the findings revealed that the SMA mixture; prepared by adding FRP additive, SBS modified bitumen, and Viatop Premium additive; increased the rutting, aging resistance and elasticity of SMAs. Moreover, load spread ability and fatigue life revealed an increase, whereas high temperature sensitivity and tendency to crack at low temperatures decreased throughout the study. The FRP contribution rate that improves the performance characteristics of the SMA mixture to the highest level was found to be $0.7 \%$.
\end{abstract}

Keywords: Stone Mastic Asphalt (SMA); Rutting; SBS; Viatop Premium; Fiber Reinforce Polymer (FRP); creep modulus; resilient modulus

\section{Introduction}

The increase in traffic and heavy loads, and consequently the collapse of roads earlier than their term of service, leads researchers to consider improving the performance of asphalt mixtures as an important issue. They are working on new types of asphalt concrete, frequently hollow aggregate size and distribution, generally produced by low penetration and modified binder. SMA (Stone Mastic Asphalt), which is a widely used product worldwide, is one of these effective asphalt mixtures. SMA has a good resistance against rutting [1]. In order to provide stone contact gap, graded aggregates are applied for the purpose of mixing, which results in big free spaces on the mixture. The increase in the free space of the asphalt mixture decreases its resistance. Thus, to avoid the free space problem, it is recommended to fill the empty space with bitumen filler and additives to maintain an acceptable amount of air. Unlike conventional hot asphalt in which all asphalt mixture components are involved in load transfer operations, in SMA mixes the skeletal system has a major aggregate load. Furthermore, the second advantage SMA mixtures is the use of bitumen, which has a high rut resistance, high skid resistance, high durability, improved resistance to reflective cracking, better drainage condition, and reduced noise pollution [2]. With the widespread use of SMA mixtures, additives and amounts added have also been the subject of many researches. Although the initial construction costs of SMAs are high, the low cost of road maintenance as a result of lower accident rates caused in roads under construction make them highly cost effective [3]. Recent studies have shown that cracks in SMA are less than HMA [4]. Based on prior research, SBS content has been an effective additive which has 
positive effects on the performance of SMAs and the rheological properties of the binder cement [5]. Various tests including: softening point, penetration, viscosity, and frass breaking point tests have improved temperature sensitivity and stiffness of the asphalt cement modified with SBS [6]. In a study, Khodaii and Mehrara added $4 \%, 5 \%$ and $6 \%$ of SBS to bitumen to prepare a hot mixture which resulted in more resistant type of asphalt against permanent deformation. Based on their findings, the most effective results are reported for 5\% SBS samples [7]. Girdap and Oruc investigated the effect of SBS and proplast on SMA and found that Pr Plast $S$ additive had a significant effect on the improvement of SBS modified SMAs, especially in hot and rainy climates [8]. Over the past years, many studies have been done on the use of additives in SMA mixtures. SBS is one of the many materials studies that has been carried out and has a very important role in improving various properties and rheology of bitumen [9]. Asphalt mixtures containing SBS have a good behavior against the moisture damage [10]. The performance of SMA is superior to the high-down and bottom-up cracks and has a longer life span [11]. In a study conducted in Germany, special viatop fiber additives were used in SMA, which were reported to decreases bitumen drain down from SMA mixtures [12]. Also, fibers are used to articulate SMA mixtures, increase tensile strength and fatigue life and stabilize bitumen. Mineral fibers and cellulose fibers are the most common types of fibers used in SMA mixtures [13]. Carbon fiber increases the asphalt mixture's stability by decreasing the flow value along with increasing voids in the mixture. Furthermore, the addition of carbon fibers improves fatigue in asphalt via creating more resistance for structural distress in pavement or traffic loads [14]. Similarly, addition of glass fiber has been found to be beneficial to improving fatigue by increasing resistance to crack formation [15,16]. The fibrous materials and polymers used in SMA have been found to increase not only a pavement's resistance to permanent deformation, but also its overall structural stability [17]. Precursors polyacrylonitrile (PAN) fiber, rayon fiber, and pitch are the bases of the graphite or carbon fiber. The tensile stress-strain curve is linear to the point of rupture. The important feature associated with them is the lower thermal expansion coefficients compared to both the glass and aramid fibers. As an anisotropic material, the transverse modulus of carbon fiber is in an order of magnitude less than its longitudinal modulus. Also, the material has a very high fatigue and creep resistance [18].

In the same vein, the current study aims at investigating the effects of SBS and Viatop Premium and FRP additives on SMA problems such as bitumen drain down, moisture damage, fatigue, and increasing the life span of pavements.

\section{Materials and Methods}

\subsection{Material Used}

Aggregate was supplied from Bagishli bazalt mine in Macka, south part of Trabzon, Turkey. The mineral filler was the rock dust, the aggregate properties of which are presented in Table 1.

Table 1. The Properties of Aggregates.

\begin{tabular}{cccc}
\hline Properties & Method & Requirement & Values \\
\hline Coarse aggregate & & & \\
Los angeles abrasion (\%) & ASTM C131 [19] & 30 max. & 17 \\
Water absorption (\%) & ASTM C127 [20] & 5 max. & 0.75 \\
Bulk specific density $\left(\mathrm{g} / \mathrm{cm}^{3}\right)$ & ASTM C127 [20] & - & 2.625 \\
Flat and Elongated (\%) & ASTM D4791 [21] & 20 max. & 14 \\
Crushed content (two faces) (\%) & ASTM D5821 [22] & 90 min. & 98 \\
Fine aggregate & ASTM C127 [20] & - & 2.514 \\
Bulk specific density $\left(\mathrm{g} / \mathrm{cm}^{3}\right)$ & & & \\
Mineral filler & ASTM C127 [20] & - & 2.757 \\
Bulk specific density $\left(\mathrm{g} / \mathrm{cm}^{3}\right)$ & & &
\end{tabular}


The asphalt cement used in the current study was AC-60/70, provided from Pasargad Oil Company, Tehran, Iran. Physiochemical properties of this cement are provided in Table 2.

Table 2. The physical properties of asphalt cement.

\begin{tabular}{cccc}
\hline Parameter Measured & Test Method & Requirement & Test Value \\
\hline Specific gravity at $25^{\circ} \mathrm{C}(\mathrm{g} / \mathrm{cm} 3)$ & ASTM D70 [23] & - & 1.021 \\
Penetration at $25^{\circ} \mathrm{C}(0.1 \mathrm{~mm})$ & ASTM D5 [24] & - & 63 \\
Softening point $(\mathrm{R} \& \mathrm{~B})\left({ }^{\circ} \mathrm{C}\right)$ & ASTM D36 [25] & - & 50.2 \\
Ductility at $25^{\circ} \mathrm{C}(\mathrm{cm})$ & ASTM D113 [26] & Min. 100 & 104 \\
Solubility in Trichloroethylene $\%$ & ASTM D-2042 [27] & Min. 99 & 99.4 \\
Flash point $\left({ }^{\circ} \mathrm{C}\right)$ & ASTM D 92 [28] & - & 256 \\
Frass breaking point $\left({ }^{\circ} \mathrm{C}\right)$ & BS EN 12593 [29] & - & -10 \\
\hline
\end{tabular}

SBS copolymer was provided from a company in Germany. The Physical properties of SBS are shown in Table 3.

Table 3. Properties of styrene-butadiene-styrene.

\begin{tabular}{ccccc}
\hline Properties & Test Method & Unit & Typical Value & Specification Limits \\
\hline Styrene content & ASTM D1416 [30] & \%wt & 31.5 & $30.5-33.5$ \\
Hardness & ASTM D2240 [31] & Shore A & 74 & $72-78$ \\
Specific weight at $23^{\circ} \mathrm{C}$ & ASTM D792 [32] & g/L & 0.93 & $0.92-0.95$ \\
\hline
\end{tabular}

The Viatop Premium used in this study was provided from JRS Company, Germany. Physiochemical properties of Viatop premium are presented in Table 4.

Table 4. The Properties of Viatop premium.

\begin{tabular}{cc}
\hline Properties & Value \\
\hline Bitumen content $(\%)$ & $10,50 / 70 \mathrm{AC}$ \\
Cellulose content $(\%)$ & 90 ARBOSEL ZZ 8.1 \\
fiber length $(\mathrm{mm})$ & $2-6$ \\
fiber thickness $(\mathrm{mm})$ & $3 \pm 1$ \\
Bulk density $\left(\mathrm{g} / \mathrm{cm}^{3}\right)$ & $480-530$ \\
Flash point $\left({ }^{\circ} \mathrm{C}\right)$ & 500 \\
\hline
\end{tabular}

CARBON FABRICS FRP was supplied from ZOLTEX Company, USA. Physical properties of FRP are presented in Table 5 .

Table 5. The Properties of Fiber Reinforce Polymer (FRP).

\begin{tabular}{cc}
\hline Properties & Value \\
\hline Tensile strength $\mathrm{MPa}$ & 4137 \\
Density gr/mL $\mathrm{mL}^{3}$ & 1.81 \\
Fiber Diameter (microns) & 7.2 \\
Carbon content \% & 95 \\
\hline
\end{tabular}

\subsection{SMA Design}

Generally, there are three present methods for bituminous mix design: Marshall method, Hveem method, and Superpave method. In Marshall Method design, which was used throughout Turkey, load is applied to a cylindrical specimen of bituminous mix and the sample is monitored until its failure, as specified in the ASTM standard [33]. To determine the optimum bitumen content according to the Marshall method, three samples were prepared for each asphalt concrete containing 
$4.5,5,5.5,6,6.5$, and $7 \%$ bitumen. To make SMAs, the aggregates were heated up at $160{ }^{\circ} \mathrm{C}$ for $24 \mathrm{~h}$. Bitumen was heated up to $160{ }^{\circ} \mathrm{C}$ to determine the optimum bitumen percentage mixture. Furthermore, Marshall hammer was applied to both sides of compacted Specimens of 50 impacts to stimulate heavy traffic. The optimum asphalt cement content for the SMA was found to be $6.9 \%$, with some amount of SBS additive. Based on the previous researches $[7,8,34], 5 \%$ of SBS (including the weight of binder) was selected for adding to the preheated binder $\left(170^{\circ} \mathrm{C}\right)$. In this research the Viatop premium content was considered $0.3 \%$ of the total mixture (recommended by manufacturer) and the FRP content was 3\%, 5\%,7\% and $9 \%$ of the weight of OBC. Since the addition of FRP to the binder did not provide a homogenous mixture, it was decided to add FRP additives of $5 \mathrm{~cm}$ dimensions to the mixture in order to obtain a homogenous mixture.

\subsection{Tests}

\subsubsection{Marshall Quotient}

The Marshall quotient reflects the rigidity and resistance of asphalt against deformation. As the proportion of this ratio increased, the strength of the mixture against deformations also goes up. In order to determine this ratio, the specimens are placed inside Marshall Jacket and pressurized, which is used for estimating Marshall Stability and flow values [35].

\subsubsection{Moisture Damage}

For each SMA mixture, 6 Marshall asphalt samples were made which were listed according to the specifications given in ASTM D 4867. Three samples were dried and three samples were immersed under saturated conditions and after passing the freezing and melting cycles, they were examined with indirect tensile strength test (ITS). Then, the tensile strength ratio (TSR) was calculated as [35]:

$$
\begin{aligned}
\text { ITS } & =\frac{2 \text { Pmax }}{\pi \mathrm{Dt}} \\
\mathrm{TSR} \% & =\frac{\text { ITSwet }}{\text { ITS dry }} \times 10
\end{aligned}
$$

In this formula, ITS calculates tensile strength $(\mathrm{kPa})$ and $\mathrm{P}$ : max applied load $(\mathrm{N})$, $\mathrm{t}$ : thickness of specimen $(\mathrm{mm})$, and $\mathrm{D}$ : diameter of specimen $(\mathrm{mm})$.

Based on Report No. 425 [36] mentioned in NCHRP, the Minimum value for TSR SMA mixtures should not be less than $70 \%$.

\subsubsection{Drain Down}

The Schellenberger bitumen drain down test was used in the experimental phase of the current study. The Schellenberger experiments were performed at the optimum bitumen ratios for each mixture. Firstly, an empty glass beaker with the capacity of $1000 \mathrm{~mL}$ was weighed and then $1000 \mathrm{~g}$ of SMA mixture was prepared at $135^{\circ} \mathrm{C}$ and weighed with $1000 \mathrm{~mL}$ glass beaker by placing the weighing scale on $0.1 \mathrm{~g}$ sensitivity. The beaker was then covered and was kept in an oven at $170{ }^{\circ} \mathrm{C}$ for $1 \mathrm{~h}$. Then, the mixture was removed from the oven and discharged from the beaker without any movement. Aggregates were removed from the glass beaker in case of any adherence before weighing. During the first mixing phase of the experiment, the bitumen drain down was determined by computing the amount of bitumen [37].

\subsubsection{Nicholson Test}

The Nicholson test was carried out to determine the resistance of asphalt binder against the separation of the aggregates through the water effect [38]. Diameter between 9.5-6.3 $\mathrm{mm} 200 \mathrm{~g}$ was taken from crushed aggregates and was dried in an oven at $110^{\circ} \mathrm{C}$ after a thorough wash. An amount 
of $100 \pm 0.5 \mathrm{~g}$ of sample from washed and dried aggregate was then taken and left to stand in an oven at $140{ }^{\circ} \mathrm{C}-150{ }^{\circ} \mathrm{C}$ for $1 \mathrm{~h}$. An amount of $5.0 \pm 0.1 \mathrm{~g}$ of asphalt cement was then added to the aggregates and mixed until the aggregates were covered with asphalt. Finally, the mixture was discharged into two Petri dishes in equal amounts which were left to stand for $10 \mathrm{~min}$ at laboratory temperature and were then placed in trays containing pure water. A minimum of $3 \mathrm{~cm}$ water film was formed. Finally, the trays containing the Petri dishes were kept for $24 \mathrm{~h}$ in the oven at $60{ }^{\circ} \mathrm{C}$, which were removed after 24 $h$, and samples were visually inspected under a light from the side $[39,40]$.

\subsubsection{Resilient Modulus}

Resilient modulus test is an experiment to determine the flexibility of asphalt mixtures under dynamic loads. The test methods consist of applying the loads applied periodically and observing sudden deformations [41]. Resilient modulus (MR) of asphalt mixtures is usually measured in indirect tensile mode (ASTM D4123 [42]) and used to evaluate the elastic properties of asphalt concrete mixtures [43]. Three Marshall samples produced at each additive rate were tested for deformation control at $5{ }^{\circ} \mathrm{C}, 25{ }^{\circ} \mathrm{C}$ and $40{ }^{\circ} \mathrm{C}$. For each temperature, the test periods were $1000 \mathrm{~ms}, 2000 \mathrm{~ms}$ and $3000 \mathrm{~ms}$ and the speeds of the test were $40 \mathrm{~m} / \mathrm{s}, 60 \mathrm{~m} / \mathrm{s}$ and $80 \mathrm{~m} / \mathrm{s}$ respectively. Based on the applied load, accepted or calculated Poisson's ratio and sample height the resilient modulus (MR) was calculated as in Equation (3).

$$
\mathrm{MR}=\frac{\mathrm{P}(\vartheta+0.2734)}{\mathrm{t} \cdot \delta \mathrm{h}}
$$

where P stands for the maximum dynamic load applied $(\mathrm{N}), \vartheta$ is Poisson's proportion, $\mathrm{t}$ is length of specimen $(\mathrm{mm})$ and $\delta \mathrm{h}$ shows horizontal recoverable deformation $(\mathrm{mm})$.

\subsubsection{Fatigue Test}

There are many experiments to determine the fatigue strength of asphalt concrete. Indirect tensile fatigue test is defined as the number of load replications acting on asphalt concrete until it breaks. In addition, each sample is subjected to fatigue test at different stress levels repeating the number of loads until it causes breakage at certain stress levels $\left(\mathrm{N}_{\mathrm{f}}\right)$. The classical fatigue relationship between $\mathrm{N}_{\mathrm{f}}$ and stress $(\sigma)$ is calculated from the logarithmic graph or Equation (4).

$$
\mathrm{N}_{\mathrm{f}}=\mathrm{K}_{1}\left(\frac{1}{\sigma}\right)^{\mathrm{K}_{2}}
$$

$\mathrm{N}_{\mathrm{f}}$ : Fatigue life

$\mathrm{K}_{1}, \mathrm{~K}_{2}$ : Material characteristics

$\sigma:$ Stress

Three marshall samples prepared at the rate of each additive for the indirect tensile fatigue test were performed at $25^{\circ} \mathrm{C}$ according to ASTM D 6927 standard. Tests were carried out under controlled stress of $300 \mathrm{kPa}$. The loading period was $1500 \mathrm{~ms}, 124 \mathrm{~ms}$ of which was loading time while the remaining $1376 \mathrm{~ms}$ was the rest time. The experiment continued until the samples were completely broken and the number of repeats of the fracture were determined [44].

\section{Results and Discussion}

\subsection{Marshall Test}

The relationship between Marshall Stability and type of mixtures are shown in Figure 1. As it can be seen, the highest stability value was found in samples with 5\% SBS, 0.3\% Viatop Premium Plus, and $0.7 \%$ FRP additives. The lowest stability value was found in the samples with 5\% SBS. In samples with 5\% SBS and 0.3\% Viatop Premium, stability value increased by adding $0.3 \%, 0.5 \%, 0.7 \%$ and $0.9 \%$ FRP additive, to $6.4 \%, 11 \%, 18: 46 \%$ and $14.78 \%$ respectively. As shown in Figure 2, the highest flow 
was observed in samples with $0.3 \%$ Viatop Premium plus $0.9 \%$ FRP and the lowest yield was observed in $0.3 \%$ Viatop Premium plus $0.7 \%$ FRP samples.

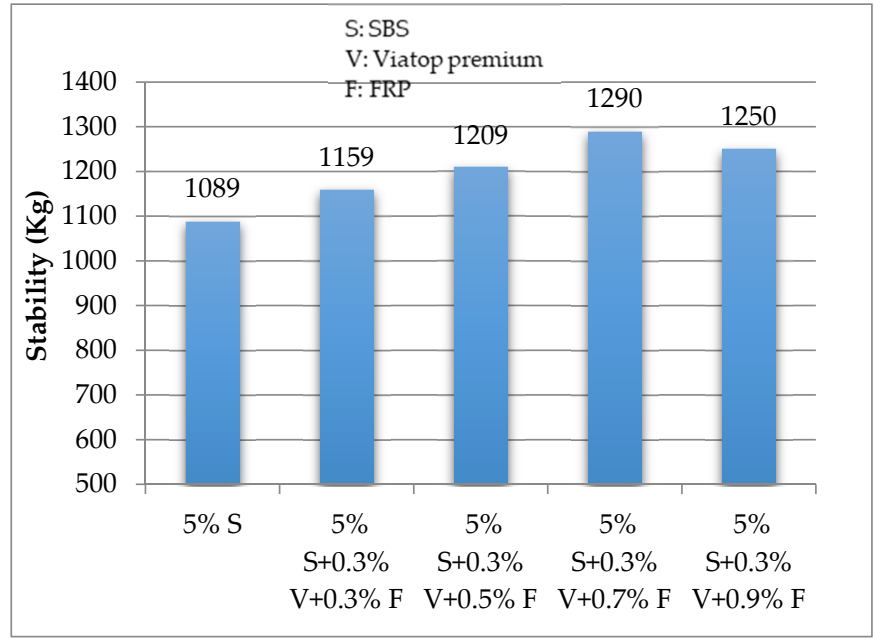

Figure 1. Results of Marshall Stability test.

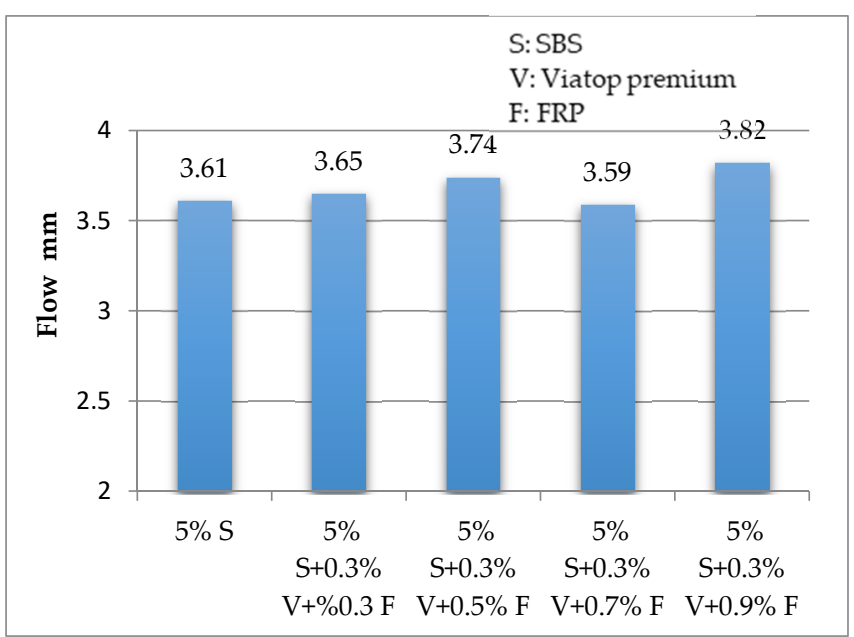

Figure 2. Results of Marshall Flow test.

\subsection{Marshall Quotient Test}

Figure 3 shows the results of the Marshall Quotient (MQ) test of the samples. The highest MQ was found in 5\% SBS plus 0.3\% Viatop Premium and 0.7\% FRP samples. Hence, it can be said that the combination of SBS plus Viatop Premium and FRP additives can increase asphalt's resistance to plastic and permanent deformations. 


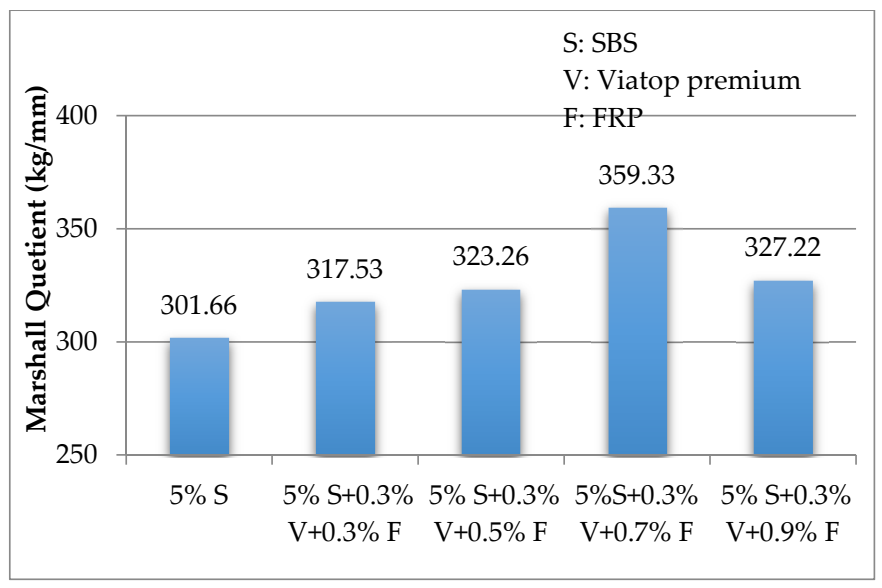

Figure 3. Results of Marshall Quotient test.

\subsection{Moisture Damage Test}

Indirect tensile strength of asphalt samples is visible in Figure 4. The increase in elastic properties of polymer-containing samples leads to an increase in their tensile strength levels. When examined in Figure 4, the indirect tensile strength of unconditional and conditional samples has increased to $0.7 \%$ of the FRP additive. The highest indirect tensile strength value was found in 5\% SBS plus $0.3 \%$ Viatop Premium and $0.7 \%$ FRP samples. The relationship between indirect tensile strength ratios (TSR) and type of mixtures are shown in Figure 5. As shown, the TSR of all mixtures are above $80 \%$ and they all pass the super pave limit. It can be said that the FRP additive increases the resistance of the mixtures against moisture damage.

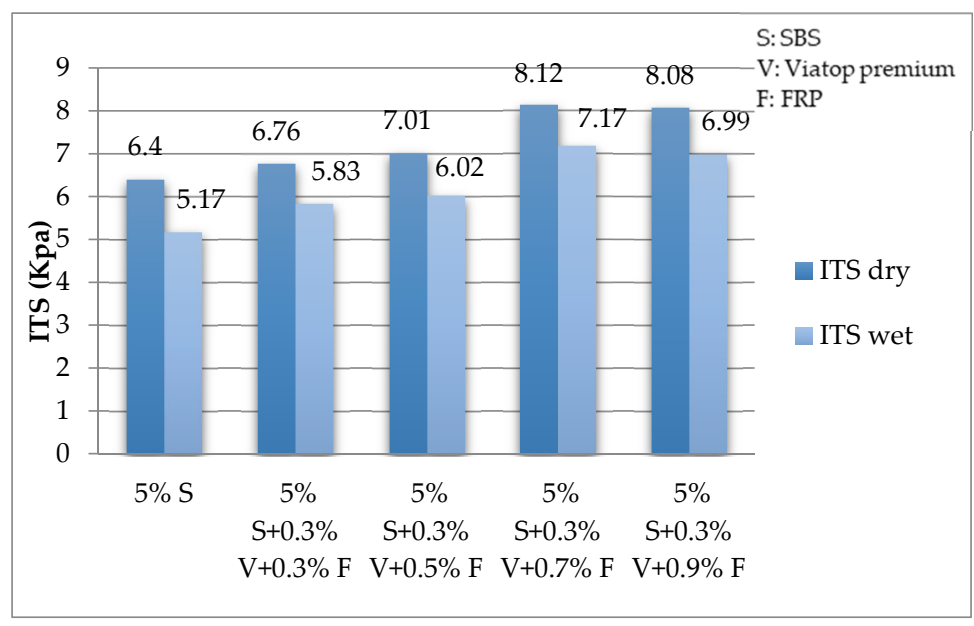

Figure 4. Results of Moisture damage test. 


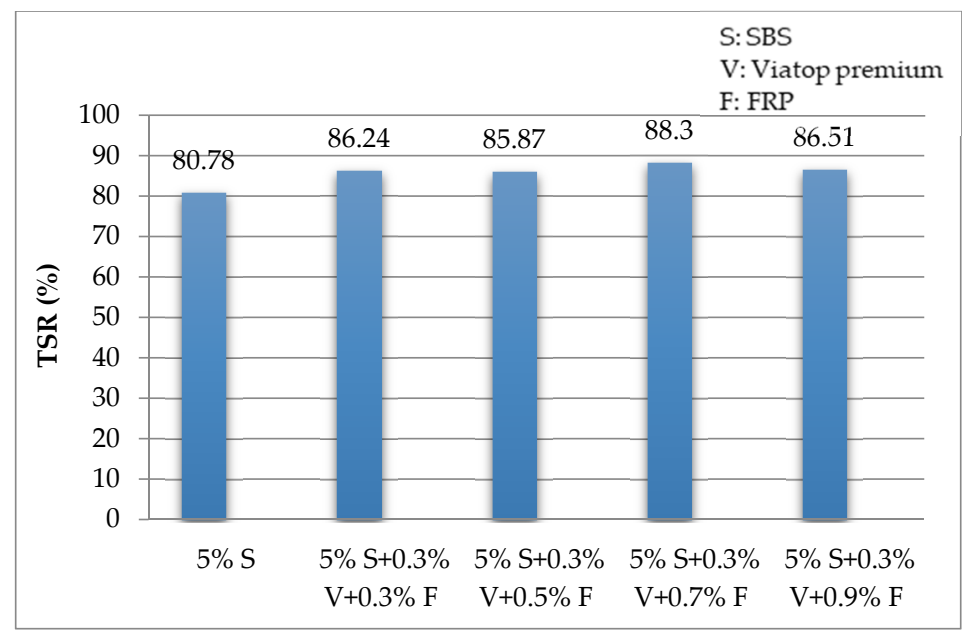

Figure 5. Results of TSR.

\subsection{Drain Down Test}

The results obtained from Schellenberger bitumen drain down test are given in Figure 6. As the results show, the mixture with $0.3 \%$ Viatop Premium and $0.9 \%$ FRP yields the best results, whereas the most disappointing result belongs to the samples with 5\% SBS in which the value is 3 times higher than the value of the samples with 5\% SBS, 0.3\% Viatop Premium and 0.9\% FRP.

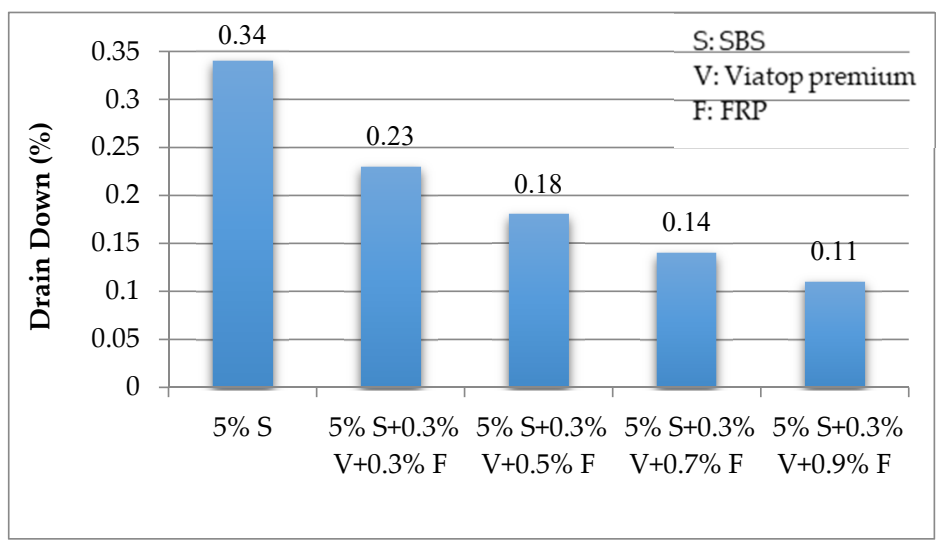

Figure 6. Results of Drain down test.

Figure 6 shows that adding $0.3 \%$ of Viatop Premium to the mixture and increasing the amount of FRP increases the resistance of SMAs against bitumen drain down. Hence, it is clear that SMAs modified with Viatop Premium and FRP are very efficient in performing against asphalt binder drain down.

\subsection{Nicholson Test}

The results of Nicholson tests are given in Table 6. It is clear that the FRP additive has no considerable effect on the adhesion of aggregates to asphalt cement. Also, the Viatop Premium additive has an insignificant effect on the adhesion among the aggregate of asphalt cement. Based on the results, SMAs modified with Viatop premium and FRP are not effective in the performance of SMAs against stripping 
Table 6. Results of Nicolson stripping test.

\begin{tabular}{cc}
\hline SMA Mixture & Stripping (\%) \\
\hline $5 \%$ SBS & 11 \\
$5 \%$ SBS $+0.3 \%$ Viatop Premium $+0.3 \%$ FRP & 9 \\
$5 \%$ SBS $+0.3 \%$ Viatop Premium $+0.5 \%$ FRP & 9 \\
$5 \%$ SBS $+0.3 \%$ Viatop Premium $+0.7 \%$ FRP & 9 \\
$5 \%$ SBS $+0.3 \%$ Viatop Premium $+0.9 \%$ FRP & 9 \\
\hline
\end{tabular}

\subsection{Resilient Modulus Test}

Figures 7-9 present the results obtained from the current experiments. As seen in the figures, the highest elastic modulus was found in samples with 5\% SBS, $0.3 \%$ Viatop Premium plus $0.7 \%$ FRP. Variation in the amount and period of loads, keeping 5\% SBS and $0.3 \%$ Viatop premium constant, resulted in an increase in FRP additives which consequently increased Elastic modulus of the samples. It can be seen that increasing FRP level to more than $7 \%$ decreases the elastic modulus of the samples. Thus, it is suggested that adding additives to pure asphalt increases its resistance against permanent deformations caused by tensile and compressive stresses caused by traffic. Also, by increasing the modulus of elasticity, the load distribution capability of asphalt coating is improved. However, as expected, in short loading times a higher elastic modulus value was obtained for each loading period. The elastic modulus values for differing temperatures, various loading periods, and different speeds were investigated according to the diagram prepared by the Asphalt Aggregate Mixture Analyzing System (AAMAS) and the flexibility modules of the mixtures were evaluated. According to the diagram, the flexibility modulus range for the temperature of $5{ }^{\circ} \mathrm{C}$ remains between about $8411 \mathrm{MPa}$ and 23,212 $\mathrm{MPa}$, while the values above this range demonstrated higher elastic modulus, and the values below revealed a lower elastic modulus. Similarly, in temperatures around $25{ }^{\circ} \mathrm{C}$ and $40{ }^{\circ} \mathrm{C}$, the appropriate elastic modulus was between $1946 \mathrm{MPa}-6205 \mathrm{MPa}$ and $781 \mathrm{MPa}-2355$ $\mathrm{MPa}$ respectively [45]. According to the test results, the elastic modulus values of all samples remained within the above-mentioned limit values specified in all temperatures.

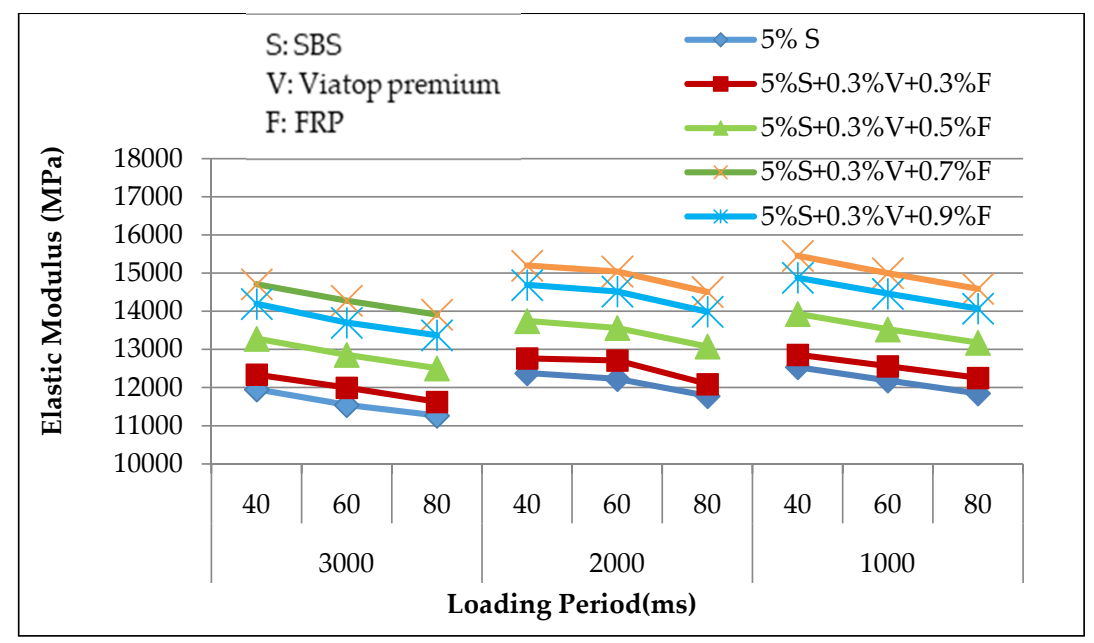

Figure 7. Resilient modulus test results, $5^{\circ} \mathrm{C}$. 


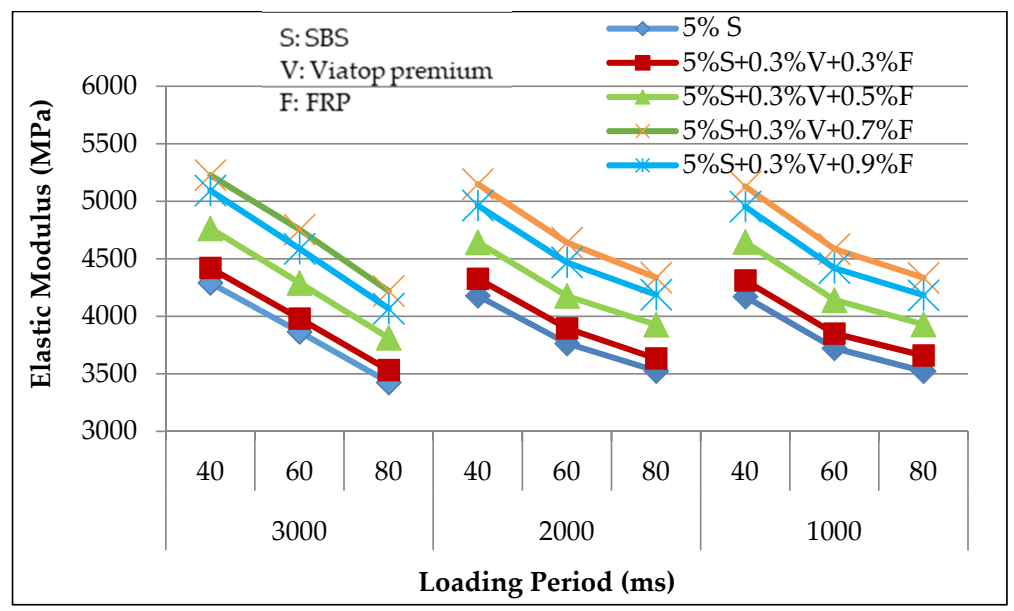

Figure 8. The result of Resilient Modulus Test at $25^{\circ} \mathrm{C}$.

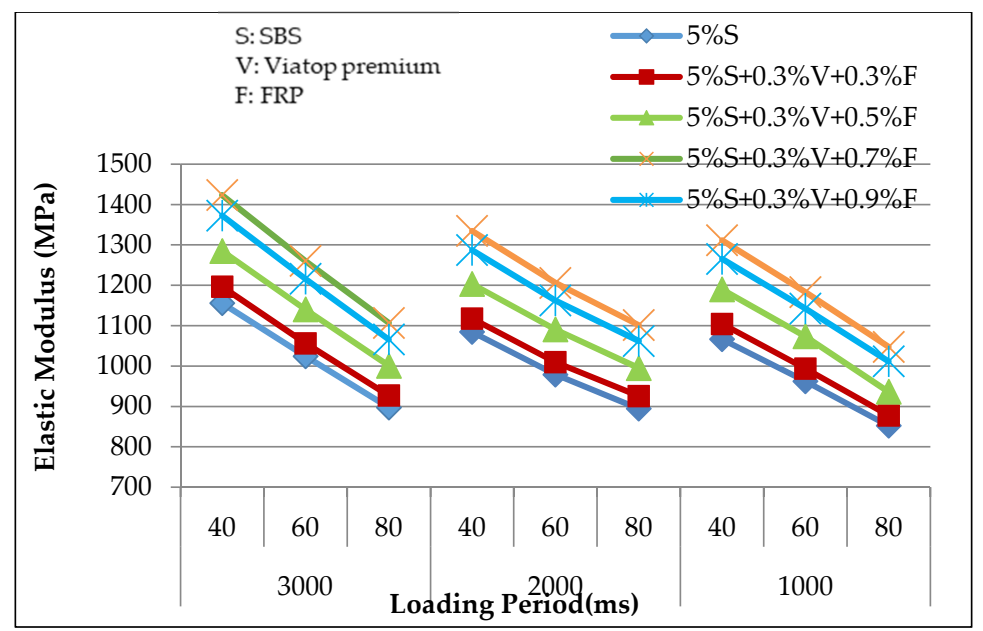

Figure 9. The result of Resilient Modulus test at $40{ }^{\circ} \mathrm{C}$.

\subsection{Static Creep Test}

For optimum asphalt content obtained from Marshall Stability test, each mixture was subjected to uniaxial static creep test at $25^{\circ} \mathrm{C}$. As shown in Figure 10, the highest amount of deformation occurred only in samples with 5\% SBS addition. The lowest amount of deformation was also found in $0.3 \%$ Viatop Premium and 0.7\% FRP added samples. Compared to the mixture with 5\% SBS modified bitumen, the deformation of samples with $0.3 \%$ Viatop Preium and $0.3 \%, 0.5 \%, 0.7 \%$ and $0.9 \%$ FRP were decreased by $3.1 \%, 8.68 \%, 15.62 \%$ and $11.47 \%$ after $3600 \mathrm{~s}$. Therefore, it was observed that the risk of rutting decreased at $0.7 \%$ FRP additive ratio. The values of creep modulus are given in Figure 11 . A thorough analysis of the graph reveals that there is a sudden decrease in creep modulus values up to $200 \mathrm{~s}$ and a gentler slope in creep modulus values until the end of the experiment. The highest creep modulus was found in samples with $0.3 \%$ Viatop Premium plus $0.7 \%$ FRP and the lowest belonged to the samples with $5 \%$ SBS. Thus, it can be clearly stated that FRP additive increases the resistance of SMA mixtures against permanent deformations. 


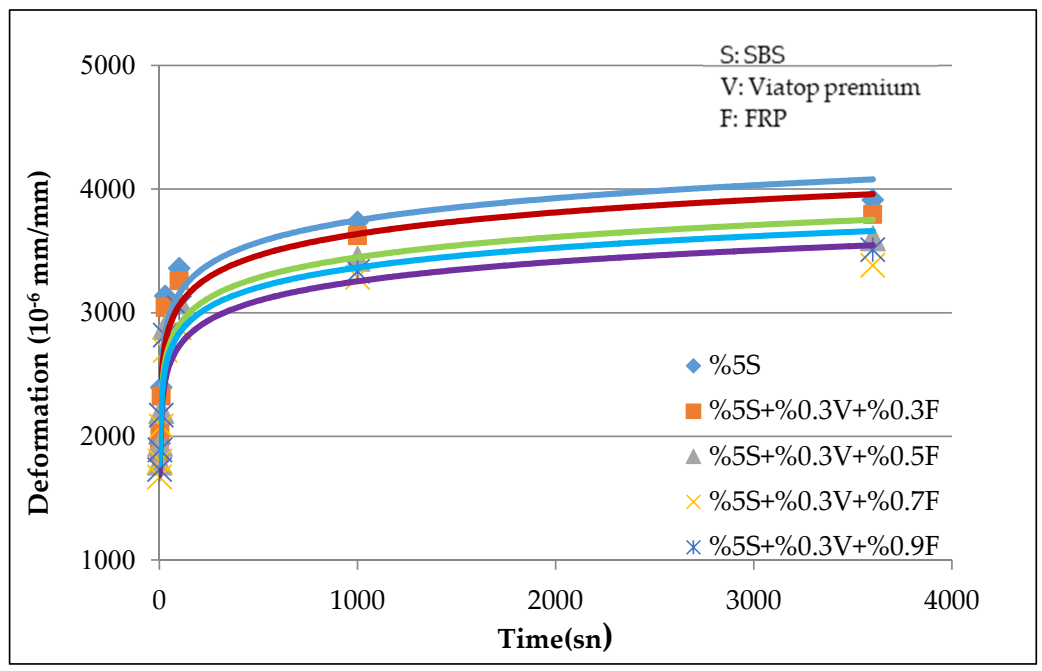

Figure 10. Variation of creep deformation over time.

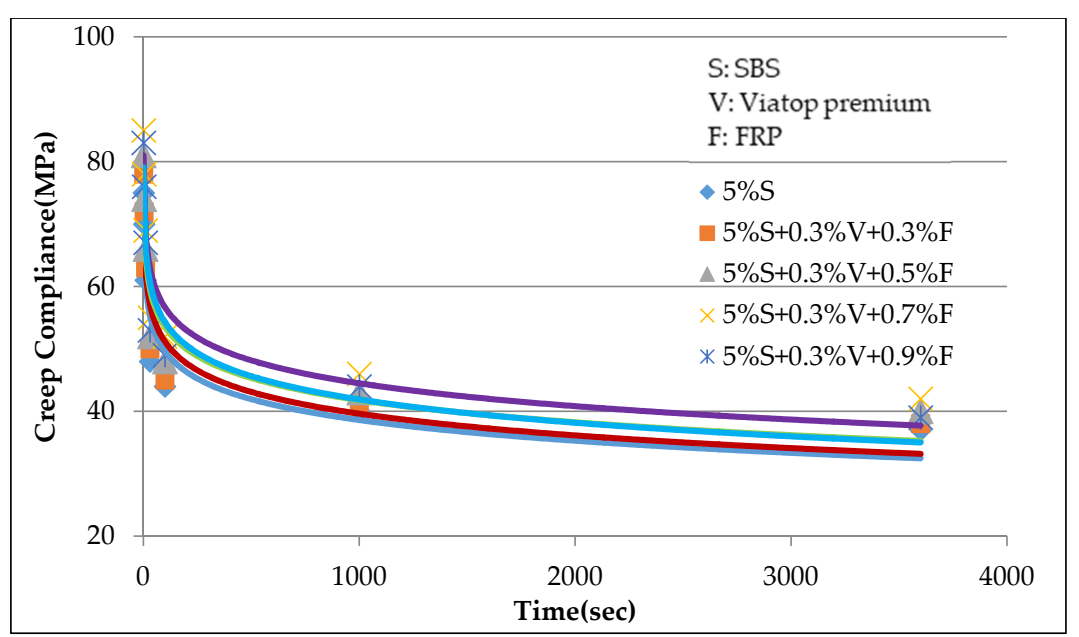

Figure 11. Creep modulus-time relationship.

\subsection{Dynamic Creep Test}

Each mixture was subjected to uniaxial repetitive creep test at $25^{\circ} \mathrm{C}$. The relationship between deformation and load repetition was shown in Figure 12. As expected, 5\% modified SMA mixture with SBS has the least resistance against rutting. The residual deformations in the mixtures decreased by increasing the amount of FRP. The variation in accumulated dynamic creep modules versus the number of cycles for all specimens were presented in Figure 13. Examining the graph reveals that there is a sudden decrease in creep modulus values up to 2000 load repetitions, and a slighter decrease in creep modulus values after load repetitions. 


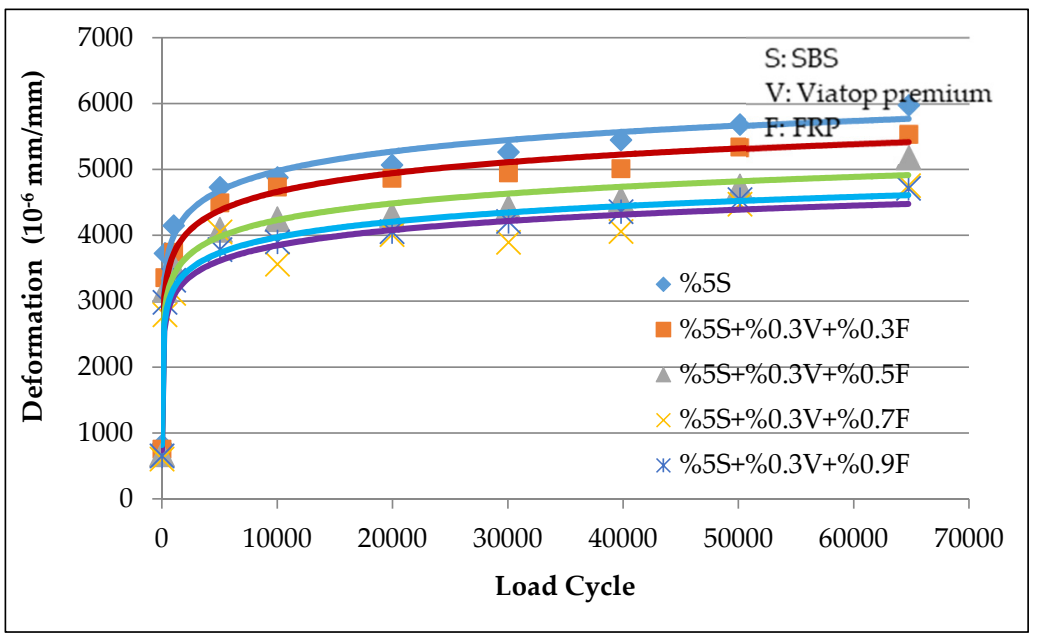

Figure 12. Deformation-Load Repetition.

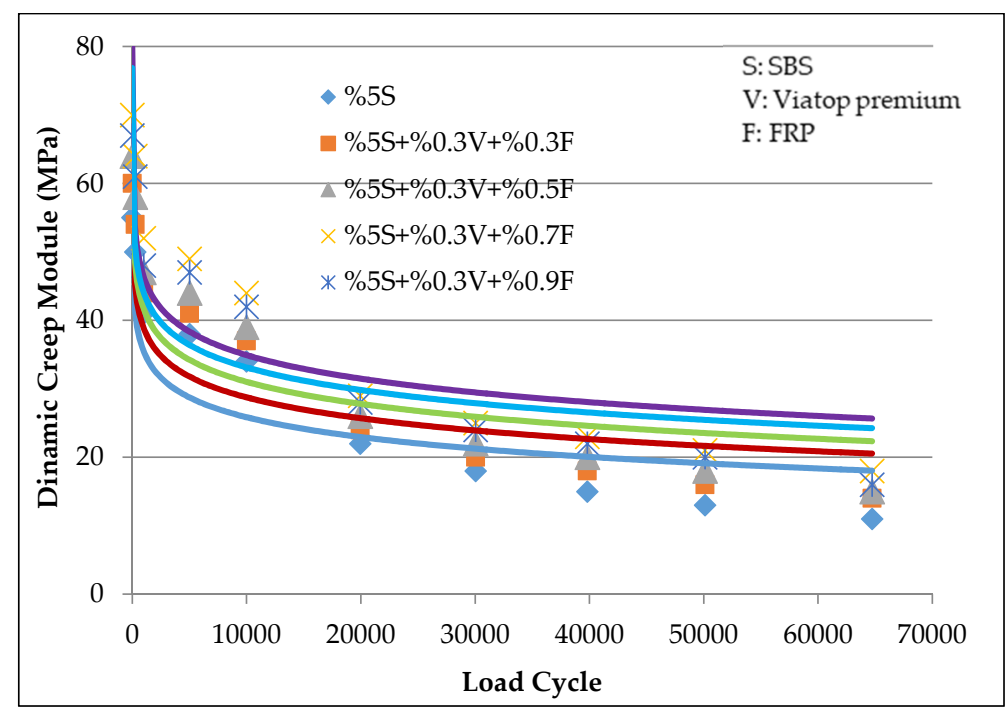

Figure 13. Dynamic Creep Modulus-Load Repetition.

According to the results, there was a decrease in SMAs with SBS, Viatop premium and FRP compared to the mixtures with SBS. Mixtures containing SBS, Viatop premium and FRP exhibit lower creep modulus in the same cycle compared to the mixture with SBS, indicating greater plastic deformation in the mixture with SBS. It is suggested that the addition of nano-clay with Arbesol strengthen WMAs against deformation compared to conventional WMAs. The results also suggest that the hardness in the mixtures containing Viatop premium and FRP increased. In addition, these mixtures showed higher resistance against rutting compared to SMAs with SBS. Hence, the modified mixture is claimed to have more service life than the non-modified mixture.

\subsection{Fatigue Test}

The results of fatigue test are given in Figure 14. Following an increase in the amount of FRP additives, an increase was also witnessed in the number of load repetitions required to break the samples. The number of load repeats including $4 \mathrm{~mm}$ deformation of the mixtures and the repetition rate of samples with 5\% SBS, $0.3 \%$ Viatop Premium and $0.3 \%, 0.5 \%, 0.7 \%$ and $0.9 \%$ FRP considerably increased compared to the samples with only $\% 5$ SBS additive. 


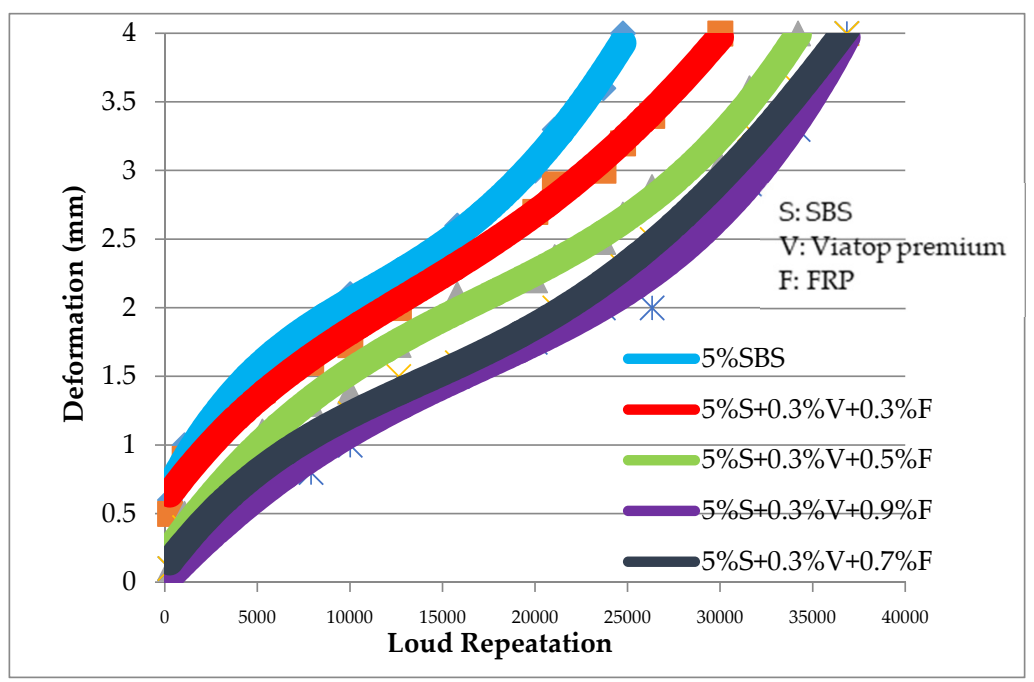

Figure 14. Results of Fatigue test.

Increasing the amount of stress on the mixture causes a break in the bond between bitumen and rock material, resulting in a rapid decrease in the hardness of the mixtures and their failure to reach fracture conditions. The results of the experiments show that adding Viatop premium and FRP was efficient in increasing the hardness of the mixtures and improving the fatigue behavior of the SMAs. The models obtained for fatigue showed that by increasing FRP content, the hardness of SMA mixtures also increased. This effect on the mixture could be due to the fiber and polymer behavior of the FPR in the mixture. So, it is suggested that adding FRP to asphalt mixture significantly increase fatigue life.

\section{Conclusions}

- According to the results taken from the Marshall Stability test, the highest stability value was found in samples containing $0.3 \%$ Viatop Premium plus $0.7 \%$ FRP. The lowest stability value was found in samples with $5 \%$ SBS. The stability values of $0.3 \%, 0.5 \%, 0.7 \%$ and $0.9 \%$ FRP and $0.3 \%$ Viatop Premium added mixtures were also increased by $6.4 \%, 11 \%, 18.46 \%$ and $14.78 \%$ respectively. The highest yield value was observed in samples containing $0.3 \%$ Viatop Premium plus $0.9 \%$ FRP and the lowest yield value was found in samples containing $0.3 \%$ Viatop Premium plus $0.7 \%$ FRP.

- The highest Marshall quotient value was found in samples with $0.3 \%$ Viatop Premium plus $0.7 \%$ FRP and the lowest was found in samples with 5\% SBS. Marshall quotient values of $0.3 \%, 0.5 \%$, $0.7 \%$ and $0.9 \%$ FRP and $0.3 \%$ Viatop Premium added mixtures were increased by $5.2 \%, 7.16 \%, 19.1 \%$ and $8.4 \%$ respectively. Therefore, it is suggested that combining mixtures with SBS along with Viatop Premium and FRP increases asphalt resistance against plastic and permanent deformations.

- The results of indirect tensile strength test also revealed an increase in indirect tensile strength values from $0.3 \%, 0.5 \%, 0.7 \%$ and $0.9 \%$ FRP and $0.3 \%$ Viatop Premium to $3.67 \%, 21.27 \%, 29.57 \%$ and $25.11 \%$, respectively. Thus, it has been observed that the FRP additive, together with SBS and Viatop Premium, increased the resistance of SMA mixture against tensile stresses under traffic loads.

- According to the results obtained from indirect tensile test, the highest elasticity modulus was found in $0.3 \%$ Viatop Premium and $0.7 \%$ FRP added samples. Keeping loading periods and load increase times constant, $0.3 \%$ Viatop Premium led to an increase in elasticity modulus along with the increase in the proportions of FRP additives. The additional FRP $(0.9 \%$ FRP) after $0.7 \%$ resulted in a decrease in the modulus of elasticity. Thus, it is proposed that the FRP additive increases the resistance of SMA mixture against permanent deformations caused by tensile and compressive 
stresses under coating layers caused by traffic loads. The resultant fatigue cracks are improved by increasing elasticity modulus, which improves load dissipation capability of the coating.

- Mixtures with $0.3 \%$ Viatop Premium and $0.9 \%$ FRP yield the best results in the bitumen drainage test, whereas the worst value belonged to 5\% SBS design. The value was 3 times more in comparison with the value of mixtures with the most positive value $0.3 \%$ Viatop Premium and $0.9 \%$ FRP.

- According to the results of the water damage (modified Lottman) test for determining the resistance of mixtures against moisture damage, it was observed that the FRP additive increased the resistance of the mixtures against moisture damage and met the Superpave specification limit of $80 \%$. Based on the results, it can be clearly stated that the FRP additive significantly increases the mixtures' resistance against moisture damage.

- The values obtained from Nicholson stripping tests revealed that FRP additive was not effective on the adhesion between the aggregates. Viatop Premium additive also made a little contribution to the Adhesion among aggregates against the water effect.

- According to the results obtained from static creep test, the highest amount of deformation was found in samples with $5 \%$ SBS. The lowest amount also belonged to the samples with $0.3 \%$ Viatop Premium plus $0.7 \%$ FRP. Compared to the mixtures with 5\% SBS, the deformation values of the mixtures with $0.3 \%, 0.5 \%, 0.7 \%$ and $0.9 \%$ FRP and $0.3 \%$ Viatop Premium decreased by $3.1 \%$, $8.68 \%, 15.62 \%$ and $11.47 \%$, at the end of $3600 \mathrm{~s}$. Thus, it was observed that the risk of rutting was minimized at $0.7 \%$ FRP additive ratio.

- Based on the results of the dynamic creep test, it is seen that there is a sudden decrease in creep modulus values up to 2000 load repetitions and a rather slight decrease in creep modulus values after 2000 load repetitions. The highest creep modulus value was obtained by mixing $0.3 \%$ Viatop Premium and $0.7 \%$ FRP. It has been found that the FRP additive improves the resistance of the mixture against permanent deformations.

- According to the results from the indirect tensile fatigue test, the load repeats of the mixtures with $0.3 \%, 0.5 \%, 0.7 \%$ and $0.9 \%$ and $0.3 \%$ Viatop Premium increased by $21 \%, 38.3 \%, 48.93 \%$ and $0.3 \%$, respectively, compared to the mixtures with $5 \%$ SBS. In conclusion, FRP additives were found to increase the fatigue resistance of the mixture, which consequently helped SMA coatings to live longer without any necessary maintenance.

Author Contributions: Conceptualization, S.S. and S.O.; methodology, S.S. and S.O.; validation, S.S. and S.O.; formal analysis, S.S.; investigation, S.S.; resources, S.S. and S.O.; data curation, S.S. and S.O.; writing-original draft preparation, S.S.; writing - review and editing, S.S.; All authors have read and agreed to the published version of the manuscript.

Funding: This research received no external funding.

Conflicts of Interest: The authors declare no conflict of interest.

\section{References}

1. Sarang, G.; Lekha, B.M.; Krishna, G.; Ravi Shankar, A.U. Comparison of Stone Matrix Asphalt mixtures with polymer-modified bitumen and shredded waste plastics. Road Mater. Pavement Des. 2016, 17, $933-945$. [CrossRef]

2. Mokhtari, A.; Nejad, F.M. Mechanistic approach for fiber and polymer modified SMA mixtures. Constr. Build. Mater. 2012, 36, 381-390. [CrossRef]

3. Bell, C.A.; Sosnovske, D.; Wieder, J.A. Aging Binder Validation; National Research Council: Washington, DC, USA, 1992; pp. 384-385.

4. Muniandy, R.; Akhir, N.; Hassim, S.; Moazami, D. Laboratory fatigue evaluation of modified and unmodified asphalt binders in stone mastic asphalt mixtures using a newly developed crack meander technique. Int. J. Fatigue 2014, 59, 1-8. [CrossRef] 
5. Wen, G.; Zhang, Y.; Zhang, Y.; Sun, K.; Fan, Y. Rheological characterization of storage-stable SBS-modified asphalts. Polym. Test. 2002, 21, 295-302. [CrossRef]

6. Ahmedzade, P.; Tigdemir, M.; Kalyoncuoglu, S.F. Laboratory investigation of the properties of asphalt concrete mixtures modified with TOP-SBS. Constr. Build. Mater. 2007, 21, 626-633. [CrossRef]

7. Khodaii, A.; Mehrara, A. Evaluation of permanent deformation of unmodified and SBS modified asphalt mixtures using dynamic creep test. Constr. Build. Mater. 2009, 23, 2586-2592. [CrossRef]

8. Girdap, E. Investigation of the Effects of Pr Plast S and SBS in Stone Mastic Asphalt Mixtures Performance. Master's Thesis, Karadeniz Technical University, Trabzon, Turkey, 2017.

9. Liu, G.; Nielsen, E.; Komacka, J.; Greet, L.; van de Ven, M. Rheological and chemical evaluation on the ageing properties of SBS polymer modified bitumen From the laboratory to the field. Constr. Build. Mater. 2014, 51, 244-248. [CrossRef]

10. Singh, M.; Kumar, P.; Maurya, M.R. Strength characteristics of SBS modified asphalt mixes with various aggregates. Constr. Build. Mater. 2013, 41, 815-823. [CrossRef]

11. Wu, S.; Wen, H.; Chaney, S.; Littleton, K.; Muench, S. Evaluation of long-term performance of stone matrix asphalt in Washington state. J. Perform. Constr. Facil. 2016, 31, 04016074. [CrossRef]

12. Sonmez, İ; Deniz, M.T.; Tayfur, S.; Ozen, H.; Yıldırım, S.A.; Eren, B.K. The Effect of Modified Additives on Bituminous Hot Mixture and Their Performance Advantages. In Proceedings of the 6th Transportation Congress, Istanbul, Turkey, 17-18 October 2005.

13. Putman, B.J.; Amirkhanian, S.N. Utilization of waste fibers in stone matrix asphalt mixtures. Resour. Conserv. Recycl. 2004, 42, 265-274. [CrossRef]

14. Jahromi, S.G.; Khodaii, A. Carbon Fiber Reinforced Asphalt Concrete. Arab. J. Sci. Eng. 2008, 33, 355-364.

15. Mahrez, A.; Karim, M.R.; Katman, H.Y. Fatigue and deformation properties of glass fiber reinforced bituminous mixes. J. East. Asia Soc. Transp. Stud. 2005, 6, 997-1007. [CrossRef]

16. Al-Hadidy, A.I.; Yi-Qiu, T. Effect of styrene-butadiene-styrene on the properties of asphalt and stone-matrix-asphalt mixture. J. Mater. Civ. Eng. 2010, 23, 504-510. [CrossRef]

17. Zweben, C. Introduction to Mechanical Behavior and Properties of Composites Materials; DCDE: Delhi, India, 1989.

18. ASTM, C131. Standard Test Method for Resistance to Degradation of Small-Size Coarse Aggregate by Abrasion and Impact in the Los Angeles Machine; ASTM: West Conshohocken, PA, USA, 2006. [CrossRef]

19. ASTM, C127. Standard Test Method for Density, Relative Density (Specific Gravity), and Absorption of Coarse Aggregate; ASTM: West Conshohocken, PA, USA, 2012. [CrossRef]

20. ASTM, D4791. Standard Test Method for Flat Particles, Elongated Particles, or Flat and Elongated Particles in Coarse Aggregate; ASTM: West Conshohocken, PA, USA, 2010. [CrossRef]

21. ASTM, D5821. Standard Test Method for Determining the Percentage of Fractured Particles in Coarse Aggregate; ASTM: West Conshohocken, PA, USA, 2017. [CrossRef]

22. TS EN 1367-1. Tests for Thermal and Decomposition Properties of Aggregates_Part 1: Determination of Resistance to Freezing and Dissolution; TSE: Ankara, Turkey, 1999.

23. ASTM, D5. Standard Test Method for Penetration of Bituminous Materials; ASTM International: West Conshohocken, PA, USA, 2013. [CrossRef]

24. ASTM, D36. Standard Test Method for Softening Point of Bitumen (Ring-and-Ball Apparatus). Annual Book of Standards; ASTM: West Conshohocken, PA, USA, 2006. [CrossRef]

25. ASTM, D113. Standard Test Method for Ductility of Bituminous Materials. Annual Book of Standards; ASTM: West Conshohocken, PA, USA, 2007. [CrossRef]

26. ASTM, D2042. Standard Test Method for Solubility of Asphalt Materials in Trichloroethylene; ASTM: West Conshohocken, PA, USA, 1976. [CrossRef]

27. ASTM, D92. Standard Test Method for Flash and Fire Points by Cleveland Open Cup Tester. Annual Book of Standards; ASTM: West Conshohocken, PA, USA, 2002. [CrossRef]

28. BS EN 12593. Bitumen and Bituminous Binders. Determination of the Fraass Breaking Point. 2015. Available online: https://shop.bsigroup.com/ProductDetail?pid=000000000030255323 (accessed on 18 March 2020).

29. ASTM D1416. Methods for Rubber from Synthetic Sources, Chemical Analysis; ASTM: West Conshohocken, PA, USA, 1996. [CrossRef]

30. ASTM D2240. Standard Test Method for Rubber Property; ASTM: West Conshohocken, PA, USA, 2000. [CrossRef] 
31. ASTM D792. Standard Test Methods for Density and Specific Gravity (Relative Density) of Plastics by Displacement; ASTM: West Conshohocken, PA, USA, 1998. [CrossRef]

32. ASTM D1559-89. Standard Test Method for Resistance to Plastic Flow of Bituminous Mixtures Using Marshall Apparatus; ASTM: West Conshohocken, PA, USA, 1994. [CrossRef]

33. Kok, B.V.; Yilmaz, M.; Kuloglu, N. Evaluation of Mechanical Properties of Asphaltite and SBS Modified Hot Mix Asphalts. J. Polytech.-Politick Derg. 2011, 14, 193-197.

34. Little, D.N. Laboratory Testing Asphalt Mixtures Incorporating Crushed River Gravel Stockpile Treated with Lime Slurry; Chemical Lime Corporation, Texas Transportation Institute: New York, NY, USA, 1994.

35. Ksaibati, K.; Hunter, E. Evaluating Moisture Susceptibility of Asphalt Mixes (No. MPC-02-138); Mountain Plains Consortium: Fargo, ND, USA, 2002.

36. Brown, E.R. Designing Stone Matrix Asphalt Mixtures for Rut-Resistant Pavements; Transportation Research Board: Washington, DC, USA, 1999.

37. Sengul, C.E. Effects of SBS and Fiber Type Additives on the Performance of SMA Compared with Lime. Ph.D. Thesis, Karadeniz Technical University, Trabzon, Turkey, 2010.

38. Umar, F.; Agar, E. Pavement Structure; Istanbul Technical University Civil Engineering Faculty Press: Istanbul, Turkey, 1991.

39. Ilıcalı, M.; Tayfur, S.; Ozen, H.; Sonmez, İ.; Eren, K. Yıldiz Technical University Publication Center, Asphalt and its Applications; Isfalt Scientific Publication 1: Istanbul, Turkey, 2001.

40. Bostancioglu, M. Development of Mechanical Properties of Bituminous Hot Mixtures with Chemical Products Obtained from Herbal Waste. Ph.D. Thesis, Karadeniz Technical University, Trabzon, Turkey, 2012.

41. ASTM D4123. Standard Test Method for Indirect Tension Test for Resilient Modulus of Bituminous Mixtures; ASTM: West Conshohocken, PA, USA, 1995. [CrossRef]

42. Orhan, F. Road Technical Requirements Performed; Highways General Directorate: Ankara, Turkey, 2012.

43. Brown, E.R.; Foo, K.Y. Evaluation of variability in resilient modulus test results (ASTM D 4123). J. Test. Eval. 1991, 19, 1-13. [CrossRef]

44. Molenaar, A.A.A.; Medani, T.O. Rational testing methods for performance based specifications. In Proceedings of the World of Asphalt Pavements International Conference, Sydney, Australia, 22-25 February 2000.

45. Von Quintus, H.L. Asphalt-Aggregate Mixture Analysis System, AAMAS (No. 338); Transportation Research Board: Washington, DC, USA, 1991. 